ORIGINAL ARTICLE

\title{
Gastrin releasing peptide receptor expression is decreased in patients with Crohn's disease but not in ulcerative colitis
}

\author{
W P ter Beek, E S M Muller, R A van Hogezand, I Biemond, C B H W Lamers
}

J Clin Pathol 2004;57:1047-1051. doi: 10.1136/icp.2003.014993

See end of article for authors' affiliations

Correspondence to: Dr I Biemond, Department of GastroenterologyHepatology, Leiden University Medical Centre, Building 1, C4-P; PO Box 9600,2300 RC Leiden, the Netherlands; i.biemond@ lumc.nl

Accepted for publication 13 May 2004
Background: Gastrin releasing peptide (GRP) and neuromedin B are bombesin (BN)-like peptides involved in regulating motility and inflammation in the gastrointestinal tract, which may be useful in treating inflammatory bowel disease (IBD). Three bombesin-like peptide receptors have been reported, but no studies have investigated their localisation in normal and inflamed human intestine.

Aim: To localise and characterise BN receptors in normal intestine and to see whether this is modified in IBD.

Methods: Full thickness intestinal tissue samples were collected from 13 patients with Crohn's disease (CD), 11 with ulcerative colitis (UC), and 19 controls. BN receptor expression was characterised and quantified with storage phosphor autoradiography using BN, GRP, neuromedin B, and the synthetic analogue BN(614) as ligands.

Results: Only BN receptor type 2 (high affinity for GRP) was present in intestinal tissue. Minimal BN binding was detected in the mucosa. In normal colonic smooth muscle, mean BN binding was $336 \mathrm{fmol} / \mathrm{g}$ tissue in longitudinal muscle, including the myenteric plexus, and $71 \mathrm{fmol} / \mathrm{g}$ in circular muscle. In CD, colonic smooth muscle BN binding was significantly decreased (longitudinal muscle, 106; circular muscle, $19 \mathrm{fmol} / \mathrm{g}$ ), in contrast to UC (377 and $62 \mathrm{fmol} / \mathrm{g}$, respectively). In CD, a small (not significant) decrease was seen in ileal muscle compared with controls $(111 v 169$ and $18 \vee 32 \mathrm{fmol} / \mathrm{g}$ tissue for longitudinal and circular muscle, respectively).

Conclusions: Only the GRP receptor is expressed in human intestine; expression is highest in longitudinal muscle and myenteric plexus of the colon. Expression is decreased in inflamed and non-inflamed colon of $C D$, but not in UC.
B ombesin (BN), a 14 amino acid peptide, was originally isolated from the skin of the amphibian Bombina bombina. ${ }^{1}$ Gastrin releasing peptide (GRP) and neuromedin $\mathrm{B}(\mathrm{NMB})$ belong to the BN-like peptide family in mammals. ${ }^{2}$ In the gastrointestinal tract, GRP is found in neurones in the human intestine and stomach. The highest amounts of NMB-like immunoreactivity are found in nerves in the circular smooth muscle of the oesophagus and rectum. Peptides from the BN family exert a variety of central and peripheral functions. In the gastrointestinal tract, they stimulate secretion from endocrine (gastrin, somatostatin) and exocrine cells (pancreas), exert direct effects on smooth muscle, and they have mitogenic effects. ${ }^{3}$ In vitro studies have shown that BN-like peptides also have immunoregulatory functions: GRP is a potent chemoattractant of macrophages and lymphocytes, ${ }^{5}$ and is also able to enhance the phagocytic process in macrophages ${ }^{6}$ and to stimulate cellular cytotoxicity and natural killer activity in human peripheral blood and lamina propria mononuclear cells. ${ }^{7-9}$

"In vitro studies have shown that bombesin-like peptides also have immunoregulatory functions"

In humans, there are three receptors for the BN-like peptides, namely: the NMB receptor, with a high affinity for $\mathrm{NMB}^{10}$; the GRP receptor, with a high affinity for $\mathrm{GRP}^{11-13}$; and the $\mathrm{BN}$ receptor subtype 3 (BRS-3), ${ }^{14}{ }^{15}$ for which the natural ligand is not yet known. All three receptors belong to the family of seven transmembrane domain G protein coupled receptors. In rats, BN binding sites were localised to the circular muscle of the gastric fundus and antrum, the submucosal layer of the small intestine, and the longitudinal and circular muscle and submucosal layers of the colon. ${ }^{16}$ In humans, the NMB receptor is found in the mucularis mucosa of the oesophagus, whereas the GRP receptor is present in the pancreatic acini. ${ }^{17}$ In addition to being abundant in the oesophagus and pancreas, $\mathrm{BN}$ receptors are also present in ileal and colonic smooth muscle, but not in epithelial cells. ${ }^{18-20}$ Until recently, little was known about BRS-3 because of the lack of a ligand. Recently, a synthetic ligand ([D-Phe ${ }^{6}, \beta$ $\left.\left.\mathrm{Ala}^{11}, \mathrm{Phe}^{13}, \mathrm{Nle}^{14}\right]-\mathrm{BN}(6-14) ; \mathrm{BN}(6-14)\right)$ became available, which binds all three BN receptors, so that by using GRP and NMB as competitive ligands all three receptors can be distinguished..$^{21}{ }^{22}$ In this way, BRS-3 has been demonstrated in human pancreatic islets. ${ }^{23}$ However, no studies with $\mathrm{BN}(6-$ 14) have been performed to characterise the $\mathrm{BN}$ receptor family in the normal human gastrointestinal tract.

Several studies have shown the ectopic expression of BN receptors in human breast, prostate, lung, and gastrointestinal carcinomas, ${ }^{13} 1924-27$ and the therapeutic use of BN antagonists has been suggested. Furthermore, technetium $\mathrm{BN}$ analogues have already been used for diagnostic purposes in clinical studies. ${ }^{28}{ }^{29}$ In addition, BN and its receptors might be of importance in inflammatory conditions. Inflammatory bowel disease (IBD) is an inflammatory disease of the gastrointestinal tract. Crohn's disease (CD) and ulcerative colitis (UC) are two different forms of IBD: CD affects the full thickness of the wall of the colon or the small intestine, whereas UC primarily affects the mucosa of the colon.

Abbreviations: $\mathrm{BN}$, bombesin; $\mathrm{BN}(6-14),\left[\mathrm{D}-\mathrm{Phe}^{6}, \beta-\mathrm{Ala}^{11}, \mathrm{Phe}^{13}\right.$, $\mathrm{Nle}^{14}$ ]-bombesin(6-14); BRS-3, bombesin receptor subtype 3; CD, Crohn's disease; GRP, gastrin releasing peptide; IBD, inflammatory bowel disease; NMB, neuromedin B; TNBS, 2,4,6trinitrobenzenesulfonic acid; UC, ulcerative colitis 
Disturbed intestinal and colonic motility, diarrhoea, and weight loss clinically characterise both diseases. Histologically, the affected tissue shows ulceration and the infiltration of inflammatory cells. ${ }^{30}$

Because the effects of BN are established only after binding with its receptor, it is important to know the BN receptor status of patients with IBD. It is known that the expression pattern of receptors for other neuropeptides, such as substance $\mathrm{P}$, is altered in IBD. ${ }^{31}$ In addition, Mantyh et al detected binding sites for BN in IBD. ${ }^{32}$

The aim of our present study was to localise and quantify all three receptors for $\mathrm{BN}$ in the human intestinal tract and to study whether this expression is modified in the inflamed and non-inflamed intestine of patients with IBD.

\section{MATERIAL AND METHODS \\ Tissue samples}

Colonic or ileal tissue samples were collected at the Leiden University Medical Centre, the Netherlands. Thirteen patients with CD and 11 with UC were included in our study and tissue was taken from both the inflamed and non-inflamed areas, as indicated by the pathologist. As normal controls, tissue was taken at least $10 \mathrm{~cm}$ from the affected site of 19 patients with a non-inflammatory related disease, mainly colonic tumours. Table 1 summarises the patients' characteristics. After surgical resection, full thickness tissue samples were immediately embedded in Tissue-Tek ${ }^{\circledR}$ OCT compound and frozen on dry ice. Tissue was stored at $-80^{\circ} \mathrm{C}$ until use.

\section{Storage phosphor autoradiography}

Storage phosphor autoradiography was used to identify the presence of receptors. The technique gives information on the localisation, quantity, and the binding characteristics of the receptors. Cryostat tissue sections $(14 \mu \mathrm{m})$ were cut at $-20^{\circ} \mathrm{C}$, mounted on gelatin coated glass slides, and stored overnight at $-80^{\circ} \mathrm{C}$. Storage phosphor autoradiography was performed according to the protocol described previously. ${ }^{33}$ Slides were incubated with $75 \mathrm{pM}{ }^{125}{ }^{\mathrm{I}-\left[\mathrm{D}-\mathrm{Tyr}^{6}, \beta \text {-Ala }\right.}{ }^{11}$, $\left.\mathrm{Phe}^{13}, \mathrm{Nle}^{14}\right]-\mathrm{BN}(6-14)$ for cold saturation studies or ${ }^{125} \mathrm{I}$ $\left[\mathrm{Tyr}^{4}\right]-\mathrm{BN}$ for quantification studies (Perkin Elmer Life Science, Boston, Massachusetts, USA). The first ligand has a high affinity for all three human receptors and the second binds preferentially with the GRP receptor. $\mathrm{BN}(6-14)$ (Polypeptide Laboratories $\mathrm{GmbH}$, Wolfenbuttel, Germany), BN, GRP, and NMB (Bachem AG, Bubendorf, Switzerland) were used as non-radioactive ligands to detect non-specific binding. Dose inhibition curves were made using different concentrations $(1 \mu \mathrm{M}-1 \mathrm{pM})$ of the non-radioactive ligands (cold saturation studies) to determine which receptor types were present. The dissociation constant, Kd, was determined using the non-linear least squares curve fitting program LIGAND $^{34}$ to obtain information about the characteristics of the receptor. Binding was quantified with a storage phosphor screen and ImageQuant ${ }^{\circledR}$ software (Molecular Dynamics, Sunnyvale, California, USA). Slides with $10 \mu \mathrm{l}$ drops of different concentrations of radiolabelled ligand were used for standardisation. Rat brain sections were used as a positive control. Binding was expressed as fmol/g tissue. Serial sections were stained with haematoxylin and eosin to distinguish the different layers in the intestine.

\section{Data analysis}

Data were expressed as mean (SEM). An unpaired Student's $t$ test was used for statistical assessment of differences between means. Values of $\mathrm{p}<0.05$ were considered significant.

\section{RESULTS}

\section{Localisation of BN binding sites}

In the colon and ileum of control patients $\mathrm{BN}$ binding was seen in the longitudinal smooth muscle layer and the myenteric plexus. Binding to the circular smooth muscle layer was weaker. A low binding signal was found in the mucosa of the colon, but not in the ileum. A similar distribution pattern was seen in the colon and ileum of patients with IBD, but the intensity in the colonic longitudinal and circular smooth muscle of patients with CD was lower than that seen in controls and patients with UC. Figure 1 provides a representative picture of the binding pattern for normal colon and the inflamed colon of a patient with CD.

\section{Identification of binding sites}

Cold saturation inhibition curves using the universal ligand ${ }^{125} \mathrm{I}-\left[\mathrm{D}-\mathrm{Tyr}^{6}, \quad \beta-\mathrm{Ala}^{11}, \quad \mathrm{Phe}^{13}, \mathrm{Nle}^{14}\right]-\mathrm{BN}(6-14)$ were performed to identify the $\mathrm{BN}$ receptor types present in the intestine of control subjects and patients with IBD. Figure 2 shows an inhibition curve of BN receptors in a control colon; this curve is also representative of the curves seen in the ileum and in patients with IBD. This inhibition curve shows that the binding sites have a high affinity for GRP and BN(614), but a lower affinity for NMB, which is characteristic of the GRP receptor. No receptors with a high affinity for NMB or only a high affinity for $\mathrm{BN}(6-14)$ (BRS-3) were detected in the human intestinal tract. The Kd for the affinity of $\mathrm{BN}$ binding was calculated using LIGAND software. For some tissues a two site model was possible, but this was never significantly better than the one site model, and the $\mathrm{Kd}_{2}$ was always extremely high (range, 235-15236nM). The mean $\mathrm{Kd}_{1}$ for BN was $2.54 \mathrm{nM}$.

Quantification of BN binding sites in control patients Binding detected by storage phosphor autoradiography was quantified using ImageQuant ${ }^{\circledR}$ software. In colonic smooth muscle of the control patients, the mean (SEM) BN binding was $183(43) \mathrm{fmol} / \mathrm{g}$ tissue, but a pronounced difference was seen between the two muscle layers. Mean (SEM) BN binding in the longitudinal muscle, including the myenteric plexus, was 336 (66) fmol/g tissue, whereas binding in the circular muscle was only $71(20) \mathrm{fmol} / \mathrm{g}$ tissue $(\mathrm{p}<0.01)$. Significantly lower binding was found in the ileum of control patients compared with the colon. The difference in binding between the longitudinal and circular muscle seen in the colon was also seen in the ileum: mean (SEM) binding was 169 (54) fmol/g and 32 (11) fmol/g ( $p=0.02)$, respectively. In the mucosa, only the colon showed a weak binding (mean, 10; SEM, $4 \mathrm{fmol} / \mathrm{g}$ tissue).

Table 1 Patient characteristics

\begin{tabular}{llllll}
\hline Group & N & $\begin{array}{l}\text { Age range in } \\
\text { years (mean) }\end{array}$ & Sex (M/F) & $\begin{array}{l}\text { Location } \\
\text { (ileum/colon) }\end{array}$ & $\begin{array}{l}\text { Inflammation } \\
\text { (yes/no) }\end{array}$ \\
\hline Controls & 19 & $34-74(55)$ & $10 / 9$ & $8 / 12$ & $0 / 20$ \\
CD & 13 & $18-73(37)$ & $3 / 10$ & $9 / 8$ & $10 / 7$ \\
UC & 11 & $19-72(40)$ & $4 / 7$ & $0 / 13$ & $8 / 5$ \\
\hline
\end{tabular}

$C D$, Crohn's disease; UC, ulcerative colitis. 


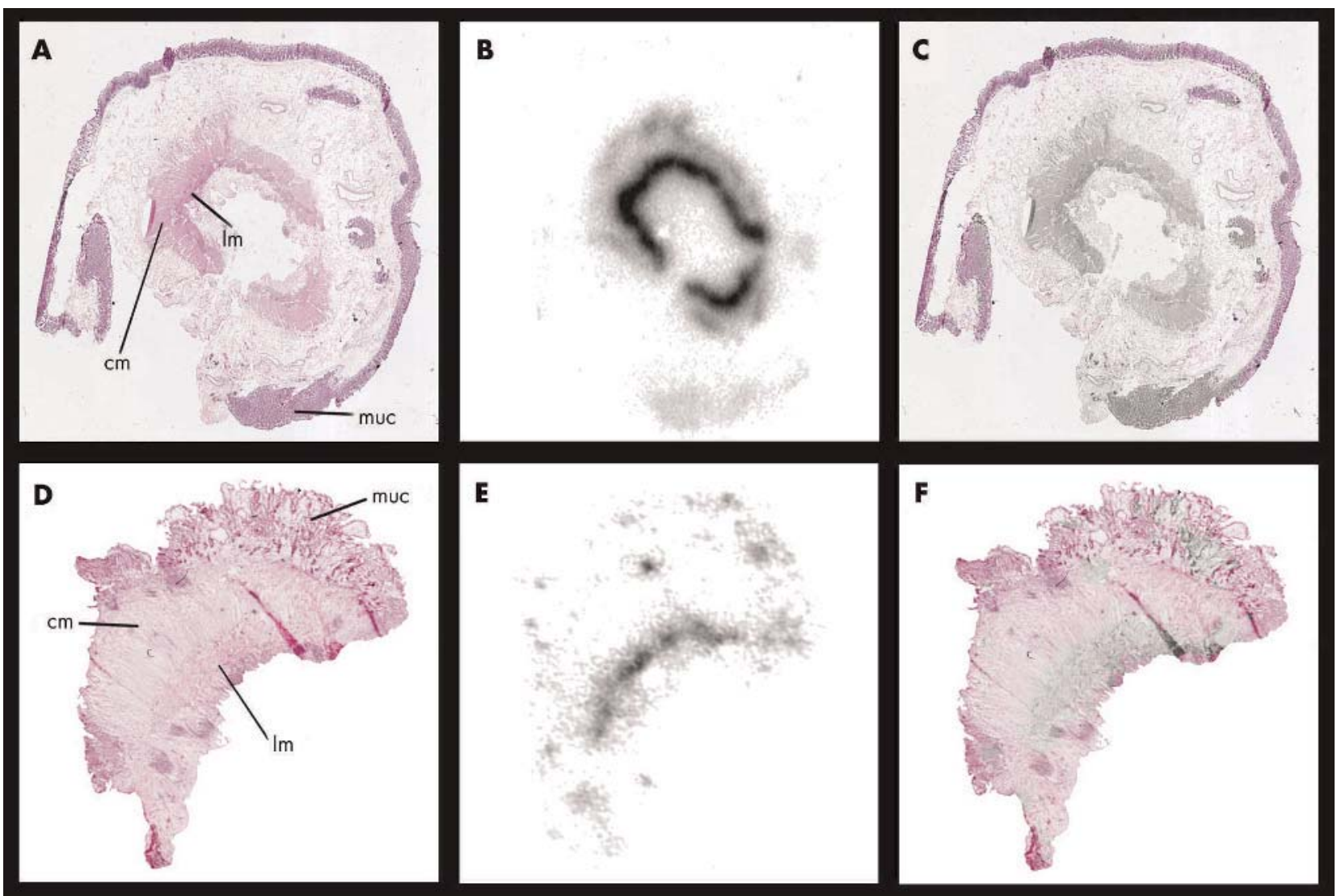

Figure $1 \quad$ 125I-BN binding to (A-C) control and (D-F) inflamed coeliac disease colonic tissue. (A, D) Haematoxylin and eosin staining. (B, E) Specific binding of ${ }^{125}$ I-BN on the serial sections; therefore, the non-specific binding image is subtracted from the total binding image. The intensity of the greyscale equals the amount of binding sites. $(C, F)$ The precise location of the BN binding sites is shown by merging the binding image with the haematoxylin and eosin stained image, which gives a qualitative result. BN, bombesin; cm, circular muscle; Im, longitudinal muscle; muc, mucosa.

Quantification of BN binding sites in patients with IBD Binding to both muscle layers was greatly decreased in the colon of patients with $\mathrm{CD}$. In the circular muscle, mean (SEM) BN binding was 19 (4) fmol/g tissue, and in the longitudinal muscle (including the myenteric plexus) binding was 106 (30) fmol/mg tissue; binding at both these sites was significantly lower than that seen in controls (fig 3 ). In patients with UC, such a decrease was not seen. Binding in both muscle layers was comparable with controls (mean (SEM), 62 (10) and 377 (58) fmol/g tissue; fig 3). In the ileal muscle of patients with CD there was also a small, although

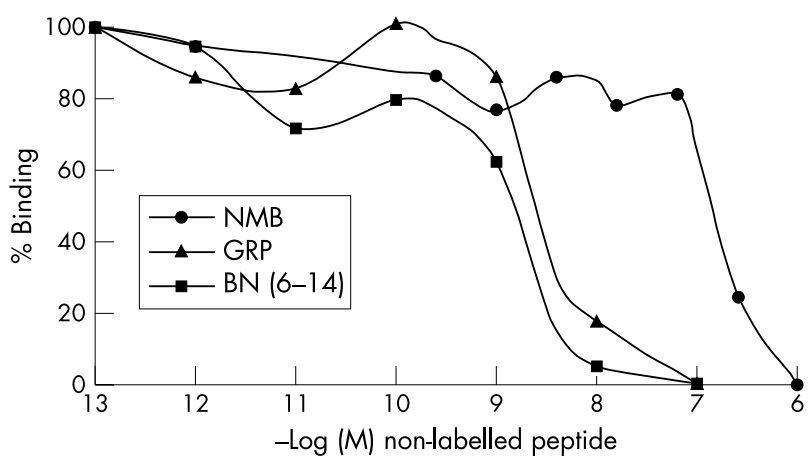

Figure 2 Competitive inhibition of ${ }^{125} \mathrm{I}-\mathrm{BN}(6-14)$ binding to human control colon. Tissue was incubated with $75 \mathrm{pM}^{125} \mathrm{I}-\mathrm{BN}(6-14)$ and the indicated concentration of NMB, GRP, and BN(6-14). BN(6-14), [D$\mathrm{Phe}^{6}, \beta-\mathrm{Ala}^{11}, \mathrm{Phe}^{13}, \mathrm{Nle}^{14}$ ]-bombesin(6-14); GRP, gastrin releasing peptide; $N M B$, neuromedin $B$. not significant, decrease compared with controls (mean (SEM), 111 (20) v 169 (54) fmol/g tissue and 18 (4) $v 32$ (10) fmol/g tissue, for longitudinal and circular muscle, respectively).

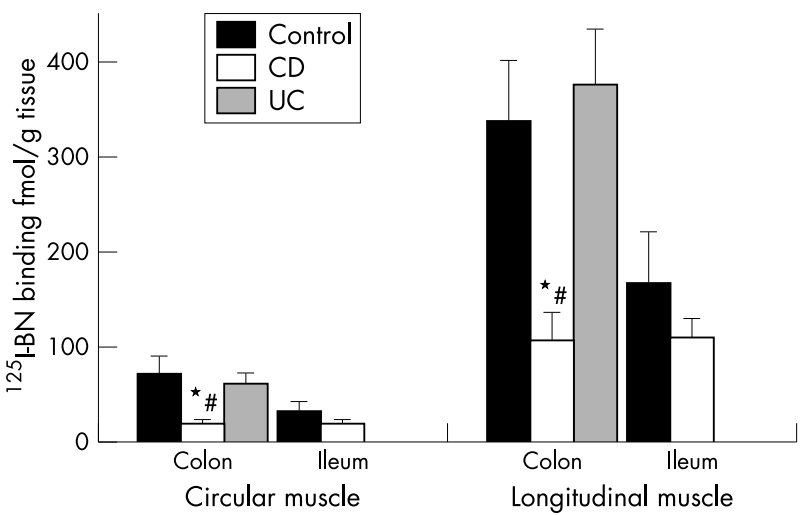

Figure 3 Quantity of ${ }^{125}$-(BN) binding to smooth muscle of human colon and ileum as detected with autoradiography. Left: BN binding to circular smooth muscle of controls, patients with $C D$, and patients with UC. The first three bars represent colonic tissue and the last two bars ileum (12, seven, 15, eight, and nine samples, respectively). Right: NT binding to longitudinal muscle, including the myenteric plexus, of controls, patients with $C D$, and patients with UC. The first three bars represent colonic tissue and the last two bars ileum (12, seven, 15, eight, and eight samples, respectively). Values are means (SEM). ${ }^{*} p<0.05$ compared with controls; $\# \mathrm{p} \leqslant 0.01$ compared with UC. BN, bombesin $C D$, coeliac disease; UC, ulcerative colitis. 
Within the CD and UC patient groups no differences were seen between inflamed and non-inflamed regions and there was no association with the use of anti-inflammatory drugs. Furthermore, no difference was detected between male and female patients in all three groups.

\section{DISCUSSION}

In our present study, we studied the quantity and localisation of receptors from the $\mathrm{BN}$ family in the mucosa and smooth muscle of the human distal intestinal tract. Both normal control patients and patients with IBD were studied. Patients with mainly colonic tumours were used as normal controls. Previous studies ${ }^{24} 27$ have shown that colon cancers can aberrantly express the GRP receptor, but that normal epithelium surrounding the cancer does not.

The cold saturation inhibition studies showed that there were no binding sites with a high affinity for NMB, indicating that there are no detectable amounts of the NMB receptor present in the human colon and ileum. In addition, no BRS-3 were detected in the human colon and ileum; when these receptors are present a binding curve with a high affinity for $\mathrm{BN}(6-14)$ and a low affinity for GRP and NMB should been seen. From these inhibition studies it can be concluded that only the GRP receptor is present in the human intestine. The highest concentrations of the GRP receptor were present in the myenteric plexus and the longitudinal smooth muscle. This finding is in agreement with a study of Rettenbacher and Reubi. ${ }^{18}$ Low numbers of binding sites were present in the mucosa of the colon only. Other studies have shown that the epithelium does not express the GRP receptor. ${ }^{18} 19$ The mucosal binding sites found in our study are probably found on neurones in the lamina propria or the muscularis mucosa, although the resolution of autoradiography was not high enough to confirm this. Immunohistochemical studies are needed to obtain information on this matter, but to date no antibodies for the GRP receptor are available.

\section{"Diagnostically, the difference between bombesin recep- tors in the colon of coeliac disease and ulcerative colitis may be useful for the differentiation between the two diseases - for example, by in vivo receptor scintigraphy"}

The receptor types present and their localisation were not altered in patients with IBD, although there was a pronounced decrease in the number of binding sites in the smooth muscle of patients with $\mathrm{CD}$ compared with the normal control patients. This decrease was not seen in patients with UC. The use of anti-inflammatory drugs did not seem to affect GRP receptor expression. CD and UC are both chronic inflammatory conditions of the intestine, but in patients with CD this is a transmural inflammation, whereas in those with UC only the mucosal layer is affected. The change in receptor expression in the smooth muscle of patients with CD but not in those with UC is in agreement with the involvement of the disease in the muscle. Previously, Mantyh and colleagues ${ }^{32}$ found no changes in BN binding sites in patients with IBD compared with controls; this discrepancy could be the result of the different methods used for quantification. Quantification with a storage phosphor screen, as used in our study, is more sensitive and has a higher dynamic range than quantification with film, as used by Mantyh et al. ${ }^{32}$

Rat studies have shown that $\mathrm{BN}$ treatment attenuated TNBS (2,4,6-trinitrobenzenesulfonic acid) induced colonic damage and stimulated histopathologically apparent mucosal proliferation in rats. $^{35}$ Earlier, Chu et al showed that BN improved survival in a lethal model of methotrexate induced
Take home messages

- Of the three mammalian bombesin-like receptors only the gastrin releasing peptide (GRP) receptor is present in the human intestine

- The expression of this receptor is highest in longitudinal muscle and the myenteric plexus of the colon

- Expression of the GRP receptor is decreased in inflamed and non-inflamed colon of Crohn's disease, but not in ulcerative colitis

- At present, the clinical relevance of our findings is unknown

enterocolitis in rats, possibly by maintaining gut mucosal structure. $^{36}$ In the mucosa of patients with IBD very few binding sites for $\mathrm{BN}$ were seen. This suggests that if the administration of BN has any effect it will be seen in the human mucosa, acting via indirect mechanisms such as the release of other trophic agents-for example, neurotensin and peptide YY.

At present, the clinical relevance of our findings is unknown. BN is known to stimulate contraction of the colonic muscles. The low expression of $\mathrm{BN}$ receptors in the intestinal muscles of patients with CD may protect the patient against enhanced motility. Alternatively, the decrease in $\mathrm{BN}$ receptors may delay intestinal healing because rat studies have shown that the administration of BN protects against TNBS induced intestinal inflammation. Our study does not allow us to draw conclusions about the potential beneficial effects of $\mathrm{BN}$ administration or blocking of the BN receptors in $\mathrm{CD}$. Diagnostically, the difference between $\mathrm{BN}$ receptors in the colon of $\mathrm{CD}$ and $\mathrm{UC}$ may be useful for the differentiation between the two diseases-for example, by in vivo receptor scintigraphy.

In conclusion, in the human colon and ileum the only BN receptor found is the GRP receptor. The highest expression is seen in longitudinal muscle and the myenteric plexus of the colon. This expression was decreased in inflamed and noninflamed colon of patients with CD, but not in patients with UC, when compared with normal colon from controls.

\section{Authors' affiliations}

W P ter Beek, E S M Muller, R A van Hogezand, I Biemond, C B H W Lamers, Department of Gastroenterology-Hepatology, Leiden University Medical Centre, 2300 RC Leiden, The Netherlands

\section{REFERENCES}

1 Anastasi A, Erspamer V, Bucci M. Isolation and structure of bombesin and alytesin, 2 analogous active peptides from the skin of the European amphibians Bombina and Alytes. Experientia 1971;27:166-7.

2 Spindel ER. Mammalian bombesin-like peptides. Trends Neurosci 1986;9:130-3.

3 Dockray GJ. Gastrin-releasing peptide (bombesin). In: Johnson LR, Alpers DH, Christensen J, et al, eds. Physiology of the gastrointestinal tract, 3rd ed. New York: Raven Press, 1994:188-92.

4 Micheletti R, Grider JR, Makhlouf GM. Identification of bombesin receptors on isolated muscle cells from human intestine. Regul Pept 1988;21:219-26.

5 Del Rio M, De la Fuente M. Chemoattractant capacity of bombesin, gastrinreleasing peptide and neuromedin $\mathrm{C}$ is mediated through PKC activation in murine peritoneal leukocytes. Regul Pept 1994;49:185-93.

6 De la Fuente M, Del Rio M, Ferrandez MD, et al. Modulation of phagocytic function in murine peritoneal macrophages by bombesin, gastrin-releasing peptide and neuromedin C. Immunology 1991;73:205-11.

7 van Tol EA, Verspaget HW, Lamers CB. Neuropeptide regulation of cellmediated cytotoxicity against human tumor cells. Neuropeptides 1990;16:25-32.

8 van Tol EA, Elzo Kraemer CV, Verspaget HW, et al. Intravenous administration of bombesin in man stimulates natural killer cell activity against tumour cells. Neuropeptides 1991;18:15-21. 
9 van Tol EA, Verspaget HW, Hansen BE, et al. Neuroenteric peptides affect natural killer activity by intestinal lamina propria mononuclear cells. J Neuroimmunol 1993;42:139-45.

10 Wada E, Way J, Shapira $\mathrm{H}$, et al. cDNA cloning, characterization, and brain region-specific expression of a neuromedin-B-preferring bombesin receptor. Neuron 1991;6:421-30

11 Battey JF, Way JM, Corjay MH, et al. Molecular cloning of the bombesin/ gastrin-releasing peptide receptor from Swiss 3T3 cells. Proc Natl Acad Sci U S A 1991;88:395-9.

12 Spindel ER, Giladi E, Brehm P, et al. Cloning and functional characterization of a complementary DNA encoding the murine fibroblast bombesin/gastrin releasing peptide receptor. Mol Endocrinol 1990;4:1956-63.

13 Corjay MH, Dobrzanski DJ, Way JM, et al. Two distinct bombesin receptor subtypes are expressed and functional in human lung carcinoma cells. J Biol Chem 1991;266:18771-9

14 Gorbulev V, Akhundova A, Buchner $\mathrm{H}$, et al. Molecular cloning of a new bombesin receptor subtype expressed in uterus during pregnancy. Eur J Biochem 1992;208:405-10.

15 Fathi Z, Corjay MH, Shapira H, et al. BRS-3: a novel bombesin receptor subtype selectively expressed in testis and lung carcinoma cells. J Biol Chem 1993:268:5979-84

16 Moran TH, Moody TW, Hostetler AM, et al. Distribution of bombesin binding sites in the rat gastrointestinal tract. Peptides 1988;9:643-9.

17 Von Schrenck T, Heinz-Erian P, Moran T, et al. Neuromedin B receptor in esophagus: evidence for subtypes of bombesin receptors. Am J Physiol 1989;256:G747-58.

18 Rettenbacher M, Reubi JC. Localization and characterization of neuropeptide receptors in human colon. Naunyn Schmiedebergs Arch Pharmacol 2001:364:291-304

19 Ferris HA, Carroll RE, Lorimer DL, et al. Location and characterization of the human GRP receptor expressed by gastrointestinal epithelial cells. Peptides 1997; 18:663-72.

20 Bitar KN, Zhu XX. Expression of bombesin-receptor subtypes and their differential regulation of colonic smooth muscle contraction. Gastroenterology 1993; 105:1672-80.

21 Pradhan TK, Katsuno T, Taylor JE, et al. Identification of a unique ligand which has high affinity for all four bombesin receptor subtypes. Eur J Pharmacol 1998;343:275-87.

22 Mantey SA, Weber HC, Sainz E, et al. Discovery of a high affinity radioligand for the human orphan receptor, bombesin receptor subtype 3 , which demonstrates that it has a unique pharmacology compared with other mammalian bombesin receptors. J Biol Chem 1997;272:26062-71.
23 Fleischmann $\mathbf{A}$, Laderach $\mathrm{U}$, Friess $\mathrm{H}$, et al. Bombesin receptors in distinct tissue compartments of human pancreatic diseases. Lab Invest 2000;80:1807-17

24 Reubi JC, Wenger S, Schmuckli-Maurer J, et al. Bombesin receptor subtypes in human cancers: detection with the universal radioligand (125)I-[D-TYR(6), beta-ALA(11), PHE(13), NLE(14)] bombesin(6-14). Clin Cancer Res 2002;8: $1139-46$

25 Sun B, Schally AV, Halmos G. The presence of receptors for bombesin/GRP and mRNA for three receptor subtypes in human ovarian epithelial cancers. Regul Pept 2000;90:77-84.

26 Chave HS, Gough AC, Palmer K, et al. Bombesin family receptor and ligand gene expression in human colorectal cancer and normal mucosa. Br J Cancer 2000;82:124-30.

27 Carroll RE, Matkowskyj KA, Chakrabarti S, et al. Aberrant expression of gastrin-releasing peptide and its receptor by well-differentiated colon cancers in humans. Am J Physiol 1999;276:G655-65.

28 Van de Wiele C, Dumont F, Vanden Broecke R, et al. Technetium-99m RP527, a GRP analogue for visualisation of GRP receptor-expressing malignancies: a feasibility study. Eur J Nucl Med 2000;27:1694-9.

29 Van de Wiele C, Dumont F, Dierckx RA, et al. Biodistribution and dosimetry of $(99 \mathrm{~m})$ Tc-RP527, a gastrin-releasing peptide (GRP) agonist for the visualization of GRP receptor-expressing malignancies. J Nucl Med 2001;42:1722-7

30 Riddell RH. Pathology of idiopathic inflammatory bowel disease. In: Kirsner JB, ed. Inflammatory bowel disease, 5th ed. Philadelphia: WB Saunders, 2000:427-50.

31 Mantyh CR, Gates TS, Zimmerman RP, et al. Receptor binding sites for substance $\mathrm{P}$, but not substance $\mathrm{K}$ or neuromedin $\mathrm{K}$, are expressed in high concentrations by arterioles, venules, and lymph nodules in surgical specimens obtained from patients with ulcerative colitis and Crohn disease. Proc Natl Acad Sci U S A 1988;85:3235-9.

32 Mantyh PW, Catton MD, Boehmer CG, et al. Receptors for sensory neuropeptides in human inflammatory diseases: implications for the effector role of sensory neurons. Peptides 1989;10:627-45.

33 Tang C, Biemond I, Appel MJ, et al. Gut peptide receptors in pancreata of azaserine-treated and normal control rats. Carcinogenesis 1995;16:2951-6.

34 Munson PJ, Rodbard D. Ligand: a versatile computerized approach for characterization of ligand-binding systems. Anal Biochem 1980;107:220-39

35 Gulluoglu BM, Kurtel H, Gulluoglu MG, et al. Bombesin ameliorates colonic damage in experimental colitis. Dig Dis Sci 1999;44:1531-8.

36 Chu KU, Higashide S, Evers BM, et al. Bombesin improves survival from methotrexate-induced enterocolitis. Ann Surg 1994;220:570-6. 